\title{
DILATATION OF THE LEFT ATRIAL APPENDAGE
}

BY

\author{
W. G. WILLIAMS \\ From Westminster Hospital, London S.W.1
}

Received January 31, 1963

Dilatation confined to the appendage of the left atrium is an unusual condition. There appear to be two varieties, one group occurring with an intact pericardium and the other in association with a pericardial defect. Only 8 examples have been reported, of which 7 were submitted to thoracotomy. Of these one was described as a diverticulum of the left atrium (Pitts and Potts, 1962), but in many respects it was similar to the cases that are the subject of this paper and is, therefore, included. The one that was not treated surgically was proven by angiography but the state of the pericardium was not known.

In this paper two further cases are described and the relevant published material reviewed.

\section{CASE REPORTS}

Patient E.A. A man, aged 27, gave no history of previous illness and presented in 1954 after mass miniature radiography of the chest (Fig. 1). This showed a lesion on the left border of the heart which was thought to be a cardiac tumour. Tomography and kymography seemed to confirm this opinion. There were no abnormal physical signs. The blood pressure was $150 / 80 \mathrm{~mm}$. $\mathrm{Hg}$ and the electrocardiogram and the rhythm were normal.

Operation, May 1954. A thoracotomy was performed through the bed of the left sixth rib. The pericardium was opened to reveal a dilated left atrial appendage measuring approximately $7 \times 5 \times 3 \mathrm{~cm}$. (Fig. 2). It did not contract, was extremely thin walled, and blood could be seen swirling within it. The body of the left atrium was normal. A clamp applied across the base of the appendage caused multiple extrasystoles.

Needle puncture or exploration of the left atrium was not performed because of the possible risk of inducing thrombosis. In view of the absence of symptoms it was felt that excision of the appendage was not indicated and the chest was therefore closed. He made a good recovery from operation apart from a minor chest infection and sinus tachycardia during the day following operation.

He remained well until January 1956, when he suffered a sudden loss of vision in the left eye with episodes of paræsthesiæ in the left arm. He attended another hospital where examination

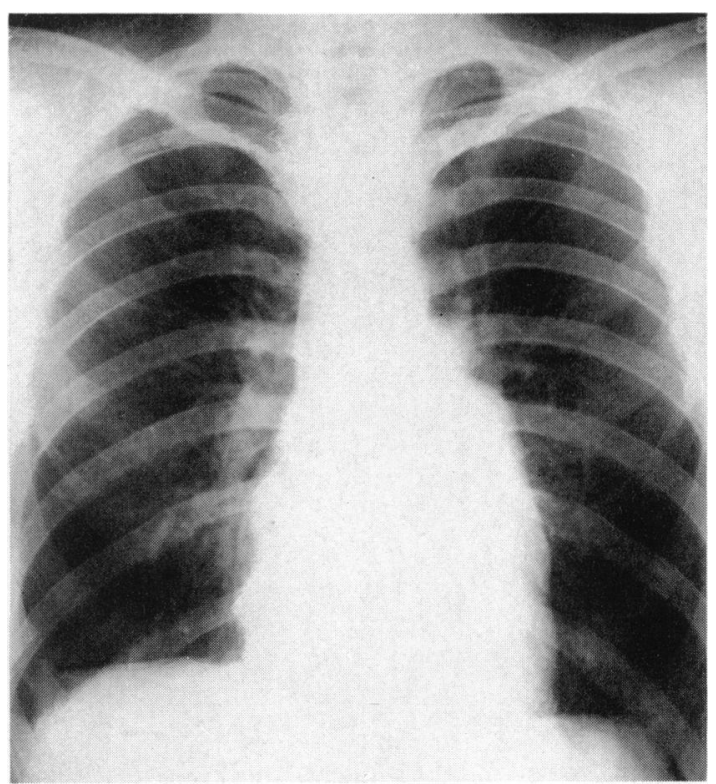

FIG. 1.-Patient E.A. Radiograph showing lesion on left border of heart. 


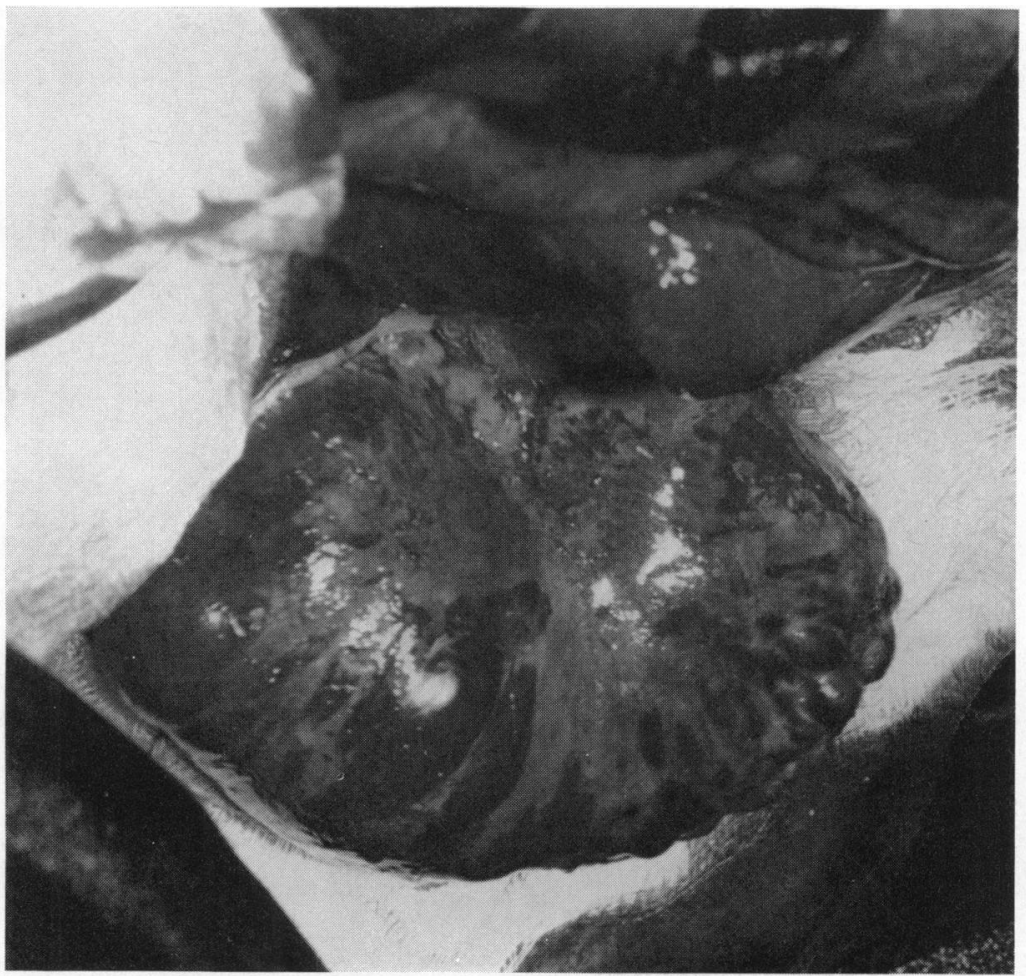

FIG. 2.-Patient E.A. Photograph at operation showing dilated atrial appendage.

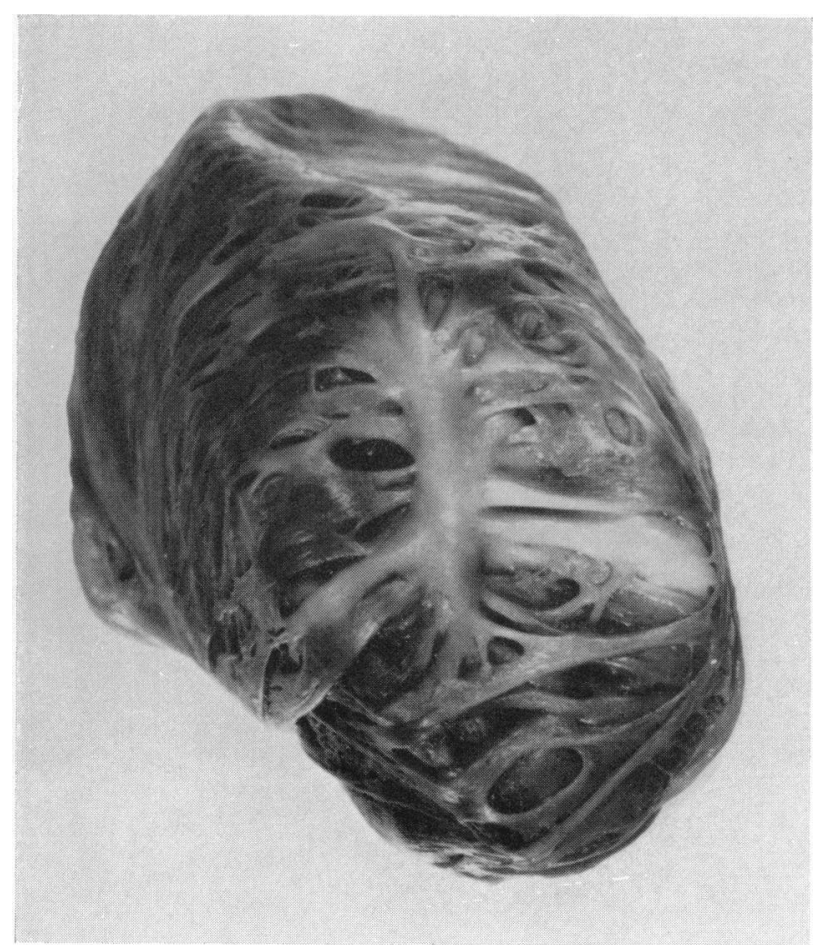

FIG. 3.-Patient E.A. Excised appendage showing thrombi in interstices of wall. showed a left upper quadrantic defect but no other changes in the central nervous or cardiovascular systems. In view of his previous history this episode was thought to be due to a cerebral embolus. Radiography of the chest was unchanged.

Operation, December 1956. A further left thoracotomy was performed. There were many dense adhesions between the left atrial appendage, the pericardium, and the lung. It was obvious that fibrosis had produced pockets in the atrial wall in which thrombi had formed. The appendage was excised and the presence of thrombi in the interstices of the wall was confirmed (Fig. 3).

Microscopical examination showed some fibrous thickening of the endocardium with a frayed network of elastic fibres. There was a thin layer of subendocardial muscle similar to those that have been described in fibro-elastosis. The myocardium was compact, thickened, and showed individual muscle fibre hypertrophy.

His discharge was again delayed by a pulmonary infection but the chest radiograph became normal.

In April 1957 he developed a tuberculous infection of the right upper lobe and 


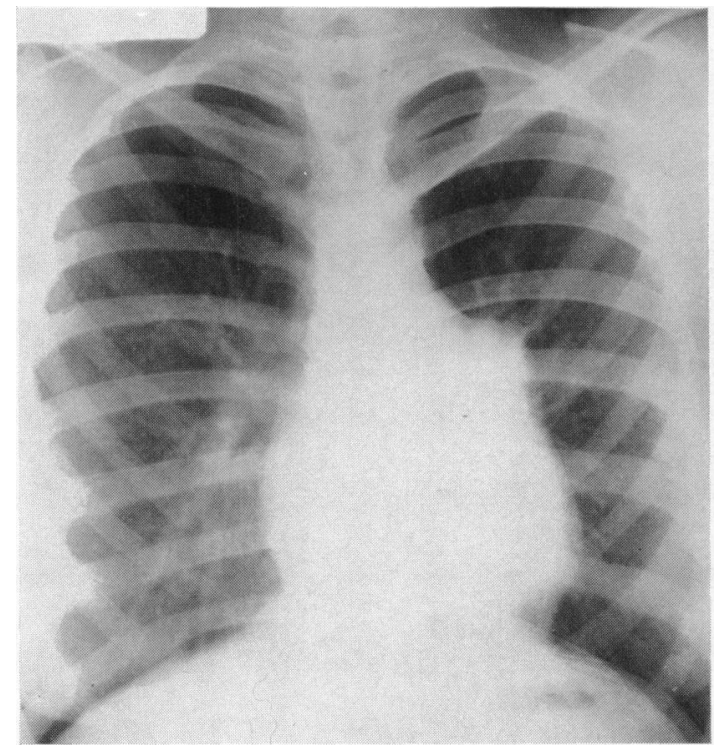

FIG. 4.-Patient V.S. Radiograph showing similarity to patient E.A.

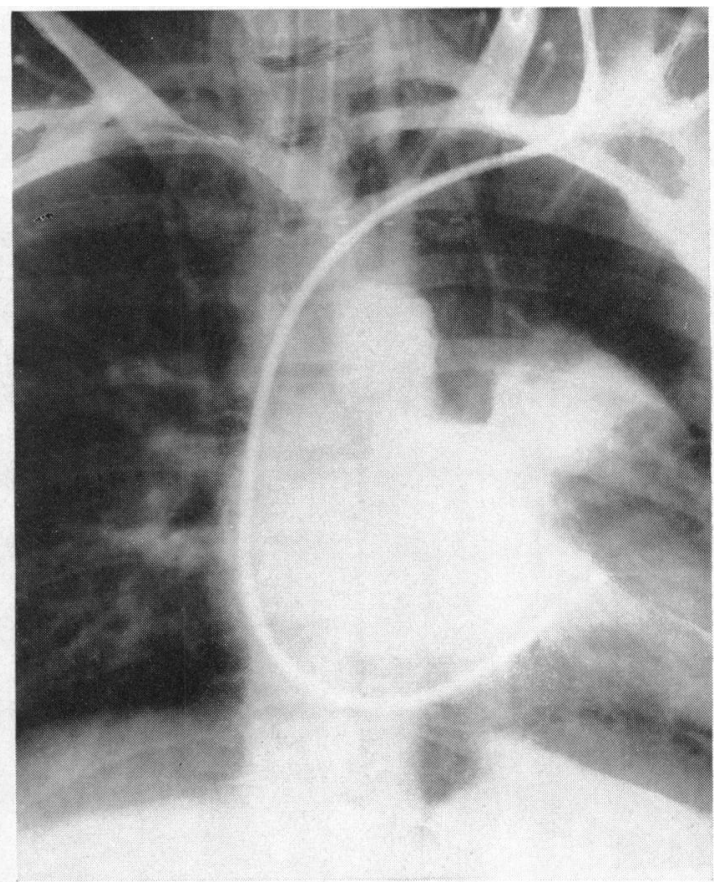

FIG. 5.-Patient V.S. Selective right ventricular angiocardiogram showing dilated left atrial appendage.

thoracoplasty was performed. In February 1962 he was well, he had no cardiovascular symptoms, and his vision had considerably improved. However, he volunteered, for the first time, the information that at the age of 12 he had a sudden temporary loss of vision in the left eye: possibly that this was an earlier cerebral embolus.

Patient V.S. A girl of 17 was referred by Professor Dragoichev of Sofia University with a tentative diagnosis of mitral valve disease. Language difficulties prevented a full history being taken, but rheumatic fever had been diagnosed at the age of 7 , and since then she had experienced indefinite weakness, vague sharp pains in the limbs, palpitation, and pain in the left chest.

The blood pressure was $120 / 70 \mathrm{~mm}$. $\mathrm{Hg}$. On one occasion a $2 / 6$ systolic murmur at the pulmonary area and a 1/4 mid-diastolic murmur at the left sternal edge were heard. (Mitral stenosis was excluded at operation.)

The electrocardiogram was normal. A chest radiogram showed a picture similar to that in our patient E.A. (Fig. 4). Right heart catheterization showed no abnormality but a selective right ventricular angiocardiogram showed a dilated left atrial appendage (Fig. 5).

In view of these findings and our experience with Case 1 it was decided that this should be excised.

Operation, April 1961. A thoracotomy was performed through the bed of the left sixth rib. There was a defect of the parietal pericardium through which a dilated left atrial appendage protruded (Fig. 6). The appendage was smaller than in the previous case. Its wall was thick and tough, and there were many adhesions between it and the pericardium and the root of the lung. The appendage was removed (Fig. 7). Histology was essentially similar to that in our previous case. There was, however, a considerable layer of fat in the epicardium and the endocardial elastic layer was absent. She made an uneventful recovery from operation and has remained well.

The relevant details of the above cases and of those previously reported are given in the Table.

\section{Dilatation of Left Atrial Appendage with Intact Pericardium}

Two certain and two doubtful cases with an intact pericardium have been reported (Palacio et al., 1960; Parmley, 1962; Pitts and Potts, 1962). 


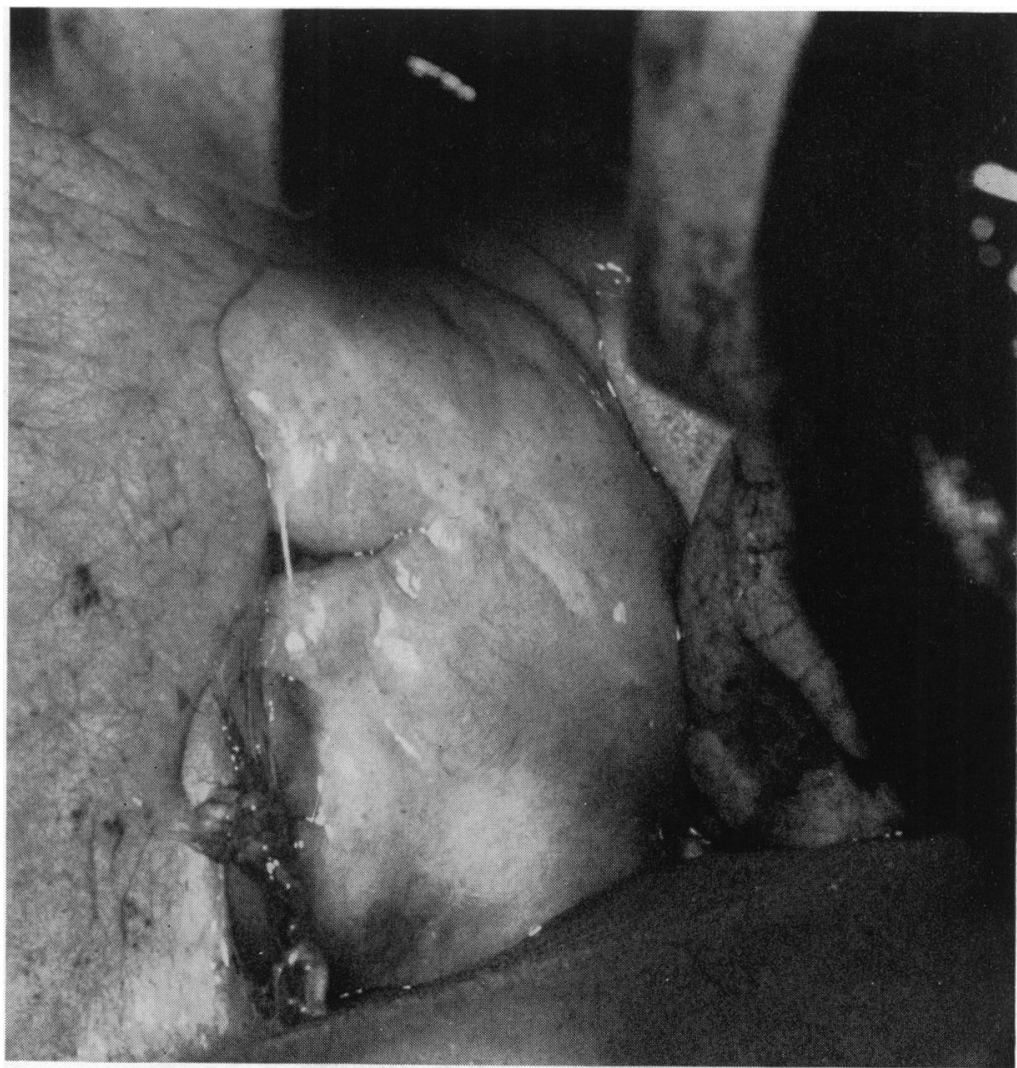

Fig. 6.-Patient V.S. Photograph at operation showing dilated left atrial appendage protruding through pericardial defect.

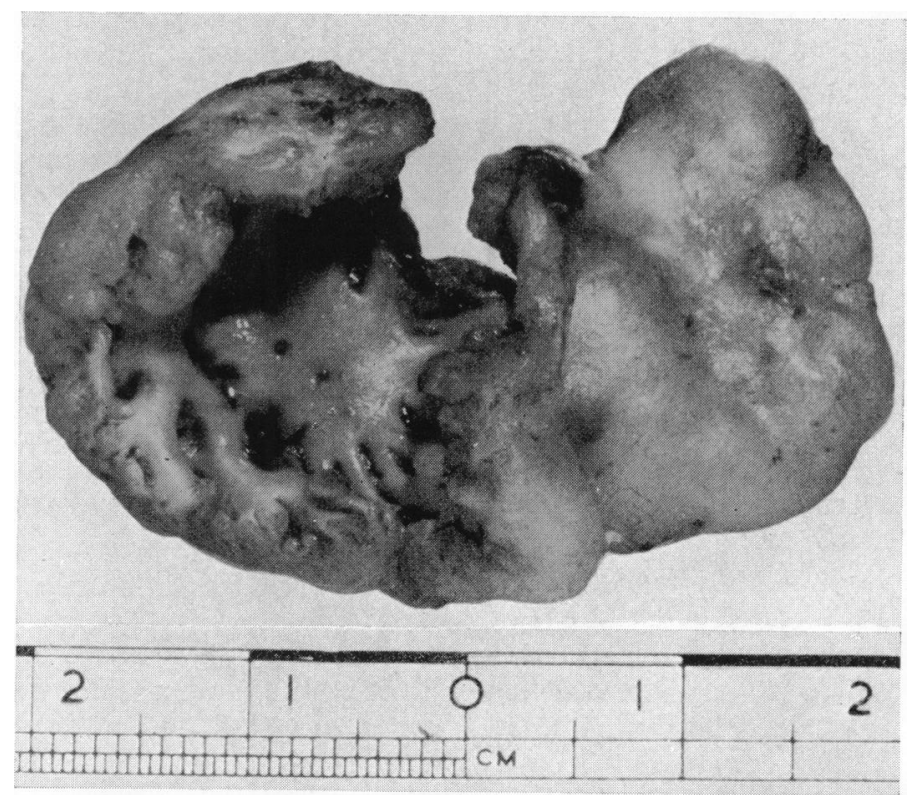

Fig. 7.-Patient V.S. The excised atrial appendage. 
TABLE

Earlier and Present Case Reports of Patients with Dilatation of Left Atrial Appendage

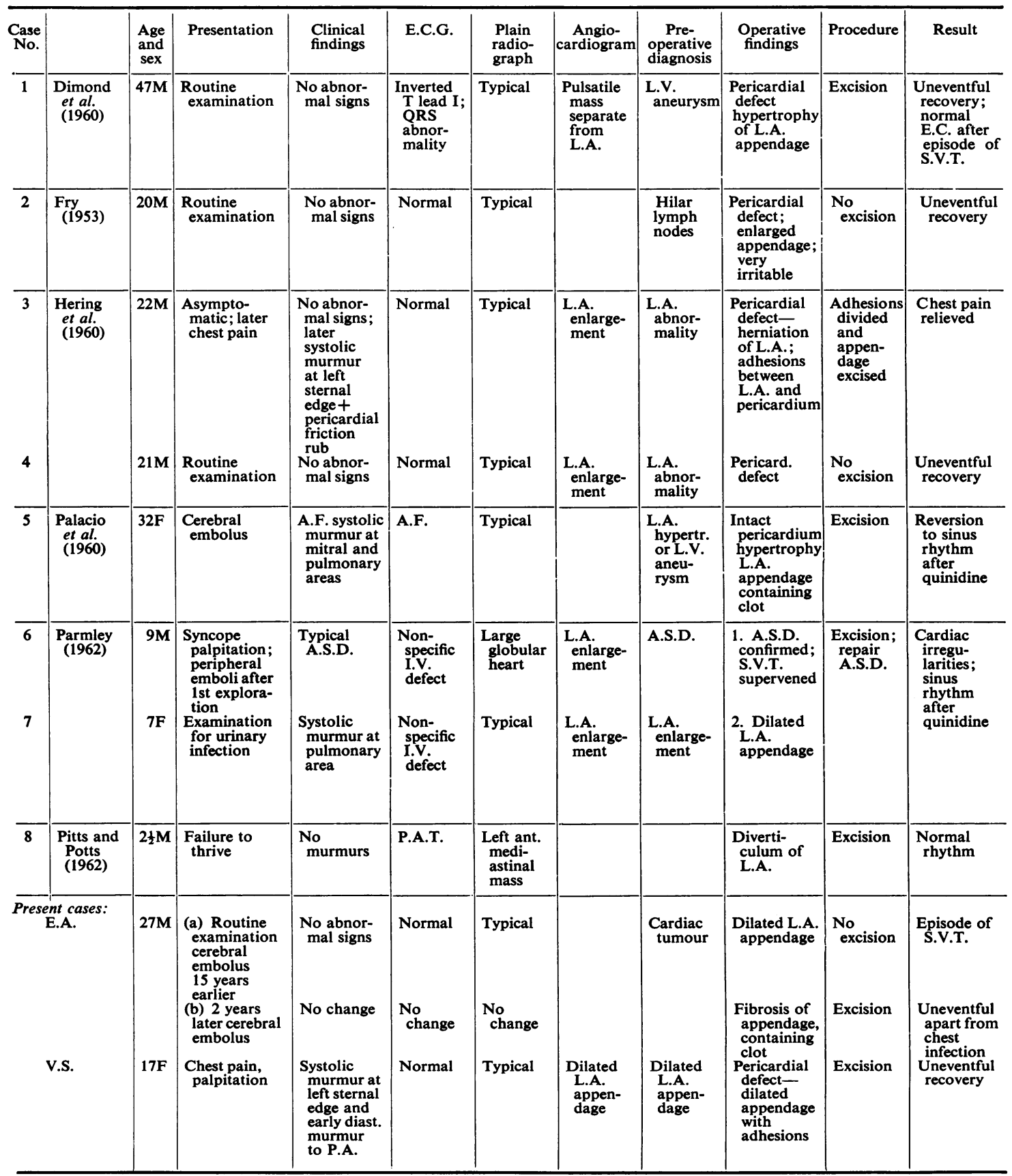

A.F. Atrial fibrillation

A.S.D. Atrial septal defect

P.A. Pulmonary area
I.V. Intraventricular

S.V.T. Supraventricular tachycardia

P.A.T. Paroxysmal atrial tachycardia 
Palacio et al. (Case 5, Table) describe a patient who presented with a cerebral embolus and atrial fibrillation. The chest radiograph of this case was very similar to our patient E.A., and the atrium was also very irritable during operation. In this case the fibrillation reverted to sinus rhythm following quinidine treatment after excision of the appendage which contained thrombi.

Parmley reported two cases. One (Case 6) was an 11-year-old boy who had an atrial septal defect of secundum type, in association with dilatation of the left atrial appendage. During exploration of the heart supraventricular tachycardia occurred and the operation was terminated. A few days later the child developed multiple systemic emboli. Four weeks later the appendage was excised and the septal defect closed by the "well technique." Normal rhythm was restored after quinidine treatment. In the second (Case 7) a dilated left atrial appendage was found by angiography during the course of investigation of a child with hypertension due to a renal artery abnormality. As this case has not been explored the presence of a pericardial defect could not be excluded.

Pitts and Potts describe a patient (Case 8) with a very large diverticulum of the left atrium, which might represent the appendage that was not mentioned in the report. This child had supraventricular tachycardia before operation. The diverticulum was successfully excised and contained thrombi.

The high incidence of abnormalities of rhythm and of systemic emboli in this group is striking.

\section{Dilatation of Left Atrial Appendage with Pericardial Defect}

Reports of four cases of dilated left atrial appendage herniating through a pericardial defect have been found.

Dimond, Kittle, and Voth (1960) (Case 1) describe a man who presented on routine examination with an abnormal chest radiograph although a film taken two years previously had been apparently normal. The cardiogram showed a QRS abnormality and the angiogram showed a pulsatile mass separate from the left atrium. At operation there was a pericardial defect with herniation of a dilated left atrial appendage which was excised. Recovery was complicated by an episode of supraventricular tachycardia.

Fry (1953) (Case 2) reports another case in which thoracotomy was undertaken for a left hilar mass: this proved to be a left atrial appendage herniating through a pericardial defect. An operation was not undertaken. The appendage was very irritable.

Two examples (Cases 3 and 4) of pericardial defect are described by Hering, Wilson, and Ball (1960). Although the report emphasized the pericardial defect, the atrial appendage appeared to have been enlarged. In the first case, the patient developed chest pain and at operation there were adhesions between the appendage and the pericardium. The adhesions were divided and the appendage excised with relief of the pain. It is interesting to note that the second case described in the present series also had adhesions and chest pain. The second case described by Hering et al. (Case 4) was explored but the appendage was not removed as the patient was asymptomatic. 1941).

A few examples have been observed in stillborn infants (Keith, 1906; Osgood and Spector,

\section{Discussion}

Clinical Features. Many patients have been asymptomatic and the lesion has only been discovered on routine examination. Three (Cases 5,6, and 10), however have presented with or developed cerebral emboli, and two have presented with chest pain (Cases 3 and 9). In both groups abnormal physical signs in the chest, if present, are confined to systolic murmurs at the left sternal edge or pulmonary area.

Many of the patients operated on have shown irritability of the appendage or post-operative arrhythmias (Dimond et al., 1960; Fry, 1953; Palacio et al., 1960; Parmley, 1962). The electrocardiogram is usually normal. Two cases described by Parmley showed a non-specific intraventricular conduction defect. Dimond et al. reported a case where there was an inverted $\mathrm{T}$ wave in 
leads I and aVL, and a peculiar rise before the QRS complex, which disappeared after excision of the appendage.

To our knowledge, dilatation of the right atrial appendage with an intact pericardium has not been described. Such a lesion could well be undetected radiologically because any opacity cast by it would be hidden by the cardiac silhouette. Furthermore, symptoms due to emboli would probably be unrecognized as being associated with a right atrial abnormality.

Atrial appendage dilatation occurring in an intact pericardium is almost certainly of congenital origin. Parmley (1962) observes that both his cases had associated congenital defects and defects of intraventricular conduction.

Treatment. Surgical intervention may be necessary to exclude a more sinister diagnosis. Whether the diagnosis is made before or at thoracotomy it seems reasonable to resect the dilated appendage which may be a source of emboli.

\section{SUMMARY}

Two patients with dilatation of the left atrial appendage are described with a review of other reported cases. Although this is a rare condition it should be possible to make a correct diagnosis. Resection of the appendage is advised to prevent emboli arising from thrombosis within its cavity.

My thanks are due to Mr. Charles Drew for his encouragement to publish these cases which were under his care, to Professor Alan Morgan for his advice on the histological appearances, and to the Photographic Department of the Westminster Hospital for the preparation of the figures.

\section{REFERENCES}

Dimond, E. G., Kittle, C. F., and Voth, D. W. (1960). Extreme hypertrophy of the left atrial appendage. The case of the giant dog ear. Amer. J. Cardiol., 5, 122.

Fry, W. (1953). Herniation of the left auricle. Amer. J. Surg., 86, 736.

Hering, A. C., Wilson, J. S., and Ball, R. E. (1960). Congenital deficiency of the pericardium. J. thorac. cardiovasc. Surg., 40, 49.

Keith, J. A. (1906). Partial deficiency of the pericardium. J. Anat. Physiol. (Lond.), 41, 6.

Osgood, R., and Spector, B. (1941). Defective pericardial sac and interatrial septum and atresia of pulmonic orifice. Amer. J. Dis. Child., 61, 1028.

Palacio, J., Guido, J. J., Noger, V. N., Gonnella, C. G., and Villegas Videla, A. F. (1960). Megaorejuela izquierda congenita. Pren. med. argent., 47, 1505.

Parmley, L. F. (1962). Congenital atriomegaly. Circulation, 25, 553.

Pitts, R. M., and Potts, W. J. (1962). Congenital diverticulum of the left atrium. Arch. Surg., 84, 334. 